\title{
Lamins at the crossroads of mechanosignaling
}

\author{
Selma Osmanagic-Myers, Thomas Dechat, and Roland Foisner \\ Max F. Perutz Laboratories, Department of Medical Biochemistry, Medical University Vienna, A-1030 Vienna, Austria
}

The intermediate filament proteins, A- and B-type lamins, form the nuclear lamina scaffold adjacent to the inner nuclear membrane. B-type lamins confer elasticity, while A-type lamins lend viscosity and stiffness to nuclei. Lamins also contribute to chromatin regulation and various signaling pathways affecting gene expression. The mechanical roles of lamins and their functions in gene regulation are often viewed as independent activities, but recent findings suggest a highly cross-linked and interdependent regulation of these different functions, particularly in mechanosignaling. In this newly emerging concept, lamins act as a "mechanostat" that senses forces from outside and responds to tension by reinforcing the cytoskeleton and the extracellular matrix. A-type lamins, emerin, and the linker of the nucleoskeleton and cytoskeleton (LINC) complex directly transmit forces from the extracellular matrix into the nucleus. These mechanical forces lead to changes in the molecular structure, modification, and assembly state of A-type lamins. This in turn activates a tension-induced "inside-out signaling" through which the nucleus feeds back to the cytoskeleton and the extracellular matrix to balance outside and inside forces. These functions regulate differentiation and may be impaired in lamin-linked diseases, leading to cellular phenotypes, particularly in mechanical load-bearing tissues.

A plethora of distinct but interconnected signaling pathways that mediate the communication between cells and between cells and their environment are essential for the development and survival of multicellular organisms. Besides signal transduction by extracellular signaling molecules and by direct cell-cell contacts, tension forces can transduce mechanical stimuli from the environment (e.g., the extracellular matrix [ECM] and blood flow) to the inside of the nucleus, where they are converted into biochemical signals, leading to changes in cell architecture, gene expression, and cellular functions. This process is called mechanosensing (Fedorchak et al. 2014). Conversely, signals from the inside of the cell are essential for

[Keywords: lamins; LINC complex; cytoskeleton; mechanosensing; mechanotransduction; extracellular matrix]

Corresponding author: roland.foisner@meduniwien.ac.at

Article is online at http://www.genesdev.org/cgi/doi/10.1101/gad.255968.114. Freely available online through the Genes \& Development Open Access option. the regulation and maintenance of the mechanical properties of the ECM (Humphrey et al. 2014). Growing evidence suggests that nuclear lamins play important roles in both the outside-in and inside-out signaling processes (Lammerding et al. 2004; Lee et al. 2007; Swift et al. 2013).

Nuclear lamins are type $\mathrm{V}$ intermediate filament (IF) proteins and the major components of the nuclear lamina, a proteinaceous network underlying the inner nuclear membrane (INM) (Dechat et al. 2010a). As IF proteins, lamins exhibit a typical tripartite structure consisting of an $\alpha$-helical rod domain flanked by globular N-terminal head and $\mathrm{C}$-terminal tail domains. The $\mathrm{C}$ terminus contains a nuclear localization signal (NLS) and a structural motif similar to a type s immunoglobulin fold (Ig-fold), likely involved in protein-protein interactions (Dhe-Paganon et al. 2002; Krimm et al. 2002; Shumaker et al. 2008). Based on structural features, sequence homologies, expression patterns, and biochemical properties, lamins are classified into A and B types (Prokocimer et al. 2009). While the major B-type lamins, lamins $\mathrm{B} 1$ and $\mathrm{B} 2$, are encoded by different genes (LMNB1 and $L M N B 2$, respectively), all A-type lamins, of which lamins $\mathrm{A}$ and $\mathrm{C}$ are the major isoforms, are encoded by a single gene (LMNA) and derived by alternative splicing. Lamins are absent from unicellular organisms and plants, but all metazoan cells examined to date express at least one B-type lamin (Cohen et al. 2001; Melcer et al. 2007; Dechat et al. 2010a). A-type lamins have only been found in Drosophila and vertebrates where they are mainly expressed in differentiated cells, while they were thought to be absent from embryonic stem cells (ESCs) and during early stages of development (Dechat et al. 2008, 2010a). However, recent studies showed that small amounts of lamins $\mathrm{A}$ and $\mathrm{C}$ are also present in mouse ESCs and in preimplantation embryos (Eckersley-Maslin et al. 2013; Kim et al. 2013).

As structural components, nuclear lamins provide shape and mechanical stability to the nucleus (Isermann and Lammerding 2013; Burke and Stewart 2014) and define the mechanical properties of the nucleus (see below). In addition, lamins have been shown to play important roles in many essential cellular functions, including gene expression, DNA replication, DNA repair, chromatin organization, cell

(C) 2015 Osmanagic-Myers et al. This article, published in Genes \& Development, is available under a Creative Commons License (AttributionNonCommercial 4.0 International), as described at http://creativecommons. org/licenses/by-nc/4.0/. 
proliferation and differentiation, cell signaling, and cell division (Dechat et al. 2008; Zuela et al. 2012; Burke and Stewart 2013; Choi and Worman 2014; Collas et al. 2014; Kennedy and Pennypacker 2014; Shimi and Goldman 2014). Despite all of their important functions, recent studies showed that lamins are not required for the proliferation and differentiation of ESCs and the proliferation of mouse embryonic fibroblasts and keratinocytes but seem to be important for later developmental processes, including tissue formation and homeostasis and organogenesis (Kim et al. 2011, 2013; Jung et al. 2014). While A-type lamins appear to play essential functions mostly during postnatal development, B-type lamins are also involved in cellular processes during embryogenesis. Mice lacking lamin B1, lamin B2, or both B-type lamins are born but are smaller than wild-type

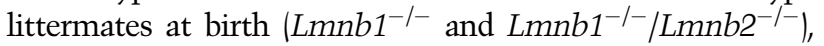
have major defects in the lungs and brain, and die within a few minutes after birth (Vergnes et al. 2004; Coffinier et al. 2010, 2011; Kim et al. 2011). Mice deficient in Lmna are born apparently normal but develop growth retardation and severe defects in skeletal and cardiac muscles after birth and die around postnatal day 16 (Sullivan et al. 1999; Kubben et al. 2011; Kim and Zheng 2013).

Over 400 mutations reported in LMNA have been found associated with $\sim 14$ distinct human diseases, but only a few disease-causing mutations have been identified in $L M N B 1$ or $L M N B 2$ (Zuela et al. 2012; Schreiber and Kennedy 2013). This suggests that mutations in B-type lamins are mostly embryonic-lethal, while phenotypes associated with mutations in LMNA become manifested only after birth. Diseases caused by mutations in genes encoding nuclear lamins are generally termed laminopathies (Worman 2012). With respect to LMNA, they comprise striated muscle diseases, such as EmeryDreifuss muscular dystrophy (EDMD) and dilated cardiomyopathy (DCM); lipodystrophic syndromes, such as familial partial lipodystrophy (FPLD); peripheral neuropathies, such as Charcot-Marie-Tooth disease; and accelerated aging disorders, including Hutchinson-Gilford progeria syndrome (HGPS) (Schreiber and Kennedy 2013).

In view of the plethora of diverse functions of lamins, loss of lamins or expression of disease-linked lamin mutants can impair many cellular processes, leading to a variety of cellular and organismal phenotypes (Prokocimer et al. 2009; Zhavoronkov et al. 2012; Zuela et al. 2012; Carboni et al. 2013). In this review, we focus on the role of nuclear lamins in mechanosensing and their specific function as a "mechanostat" that responds to changes in the ECM and at the same time regulates the ECM to match the stiffness of the tissue microenvironment with the mechanical properties of the cell. We also discuss how disease-linked lamin mutants may impair the response of cells to mechanical stimuli and influence the properties of the ECM and how this may contribute to the disease phenotype.

\section{Assembly and mechanical properties of lamins: lamins as 'shock absorbers'}

One important property of nuclear lamins, essential for most if not all of their cellular functions, is their ability to assemble into higher-order structures. Lamin assembly has been studied intensively in vitro, but there are still a lot of open questions regarding their higher-order structure organization in vivo (Zwerger and Medalia 2013). The basic subunit of lamin assembly is a parallel coiledcoil dimer (Aebi et al. 1986; Dessev et al. 1990; Gieffers and Krohne 1991; Heitlinger et al. 1991; Stuurman et al. 1996). In vitro, these dimers assemble "head to tail" to form polar filaments, which interact laterally in an antiparallel fashion to form apolar tetrameric protofilaments. These assemble into paracrystals (Stuurman et al. 1998; Zwerger and Medalia 2013) or, in the case of Caenorhabditis elegans, also into $\sim 10$-nm-thick filamentous structures (three to four protofilaments) (Karabinos et al. 2003; Foeger et al. 2006; Ben-Harush et al. 2009).

In contrast, little is known about the assembly of lamins into the nuclear lamina in vivo. Lamins are extensively modified and interact with a large number of proteins (Simon and Wilson 2011; Korfali et al. 2012), the nuclear membrane, and chromatin (Kalinowski et al. 2013; Simon and Wilson 2013), all of which can affect lamin assembly.

For example, lamin A and all B-type lamins contain a -CAAX box at their C-terminal end, which leads to their extensive post-translational processing. In a first step, a farnesyl moiety is attached to the cystein residue by a farnesyltransferase, and then the -AAX tripeptide is cleaved off by an endopeptidase, most likely Ras-converting enzyme 1 (Rce1) and/or zinc metalloprotease related to Ste24p/ FACE1 (Zmpste24); subsequently, the cysteine residue is carboxymethylated by isoprenylcystein carboxyl methyltransferase (Icmt) (Young et al. 2005; Rusinol and Sinensky 2006). While the processing of B-type lamins ends here, an additional 15 amino acids, including the farnesylated/ carboxymethylated cysteine residue, are cleaved off of the $\mathrm{C}$ terminus of lamin $\mathrm{A}$ in a final step, leading to its mature form (Bergo et al. 2002; Pendas et al. 2002; Corrigan et al. 2005). Therefore, mature B-type lamins contain a farnesyl and carboxymethyl group at their $\mathrm{C}$ termini, while mature lamin $\mathrm{A}$ and lamin $\mathrm{C}$, which do not contain a -CAAX box, lack such modifications. The -CAAX processing occurs most likely within the nucleus (Barrowman et al. 2008) and is suggested to be involved in targeting lamins to the INM and establishing protein-protein interactions (Rusinol and Sinensky 2006; Kalinowski et al. 2013). Although the permanent farnesylation/carboxymethylation of lamins leads to their stable association with membranes throughout the cell cycle, it is not a prerequisite for their incorporation into the nuclear lamina (Dechat et al. 2007, 2008).

In addition to farnesylation, lamins become extensively phosphorylated during the cell cycle (Simon and Wilson 2013; Kochin et al. 2014). Lamin phosphorylation was initially described in mitosis, where it leads to the depolymerization and solubilization of lamin structures required for nuclear envelope (NE) breakdown (Gerace and Blobel 1980; Heald and McKeon 1990; Collas 1999; Panorchan et al. 2004a; Mall et al. 2012). Upon NE reassembly at the end of mitosis, lamin dephosphorylation is required for the formation of a nuclear lamina (Thompson et al. 1997; Steen et al. 2000; Ito et al. 2007). While B-type 
lamins relocate exclusively to the periphery of the newly forming sister nuclei, A-type lamins initially accumulate within the nuclear interior during telophase and early G1 (Moir et al. 2000; Dechat et al. 2004). Besides their mitotic phosphorylation, lamins become also phosphorylated during interphase, which appears to be important for the regulation of their nuclear import and their solubility (Hennekes et al. 1993; Schneider et al. 1999; Cenni et al. 2005; Kuga et al. 2010; Mitsuhashi et al. 2010; ZarembaCzogalla et al. 2012; Buxboim et al. 2014; Kochin et al. 2014).

The molecular and structural organization of the B- and A-type lamins in the nuclear lamina is still not completely understood. For many years the lamina was thought to represent an orthogonal meshwork of 10-nm filaments, based on early electron microscopic studies in Xenopus oocyte nuclei (Aebi et al. 1986). However, such a network has not been seen in somatic cells so far. Based on the ability of lamins to form heterodimers in vitro (Schirmer et al. 2001), it was assumed that B- and A-type lamins can form heteropolymers also in vivo. However several recent studies, including fluorescence resonance energy transfer and superresolution microscopy analyses, and the expression of various lamin isoforms in Xenopus oocyte nuclei clearly revealed independent but interconnected networks of A- and B-type lamins (Goldberg et al. 2008; Schermelleh et al. 2008; Shimi et al. 2008; Kolb et al. 2011; Grossman et al. 2012). These data support a model in which the farnesylated B-type lamins, especially lamin B1, form a more regular network closely associated with the INM and the nuclear pore complexes (NPCs) while the A-type lamins form more irregular meshworks on top of the lamin B structures. This model is supported by the findings that knockdown of lamin B1 results in a dramatic increase in the mesh size of the lamin $\mathrm{A} / \mathrm{C}$ and lamin B2 networks and leads to the formation of nuclear blebs enriched in A-type lamins and deficient for B-type lamins (Shimi et al. 2008). Furthermore, studies in ESCs lacking different combinations of B- and A-type lamins and in fibroblast-like cells derived therefrom also showed that lamin $\mathrm{A} / \mathrm{C}$ and lamin $\mathrm{B} 2$ structures are dependent on lamin B1 (Guo et al. 2014), but, at sufficiently high concentration, all lamins can form a lamina on their own.

A-type lamins are also present within the nuclear interior in interphase cells, most likely due to the lack of a Cterminal farnesyl group. These nucleoplasmic lamins A/C are most prominent in early G1 cells, more dynamic than the lamins residing in the lamina, and regulated through phosphorylation and interaction with the lamina-associated polypeptide $2 \alpha$ (LAP2 $\alpha$ ) (Dechat et al. 2000, 2004; Moir et al. 2000; Naetar et al. 2008; Shimi et al. 2008; Naetar and Foisner 2009; Kolb et al. 2011; Kochin et al. 2014). Although little is known about the regulation, dynamics, and assembly state of the nucleoplasmic A-type lamins, they may be involved in a variety of cellular processes, including chromatin organization, gene expression, and cell proliferation (Dechat et al. 2010b; Gesson et al. 2014).

Recent studies have shown that lamins can form stiff yet elastic and compressible networks suggested to function as "molecular shock absorbers" (Dahl et al. 2004,
2005; Panorchan et al. 2004b). The mechanical properties of the nucleus are highly dependent on the molecular and structural composition of the nuclear lamina. For example, nuclear mechanics is impaired in lamin A/C-deficient cells and cells devoid of emerin, an integral protein of the INM that interacts with lamins (Broers et al. 2004; Lammerding et al. 2004, 2005; Rowat et al. 2006; Lee et al. 2007). Furthermore, it appears that the mechanical stiffness of the nucleus and its viscosity are solely dependent on A-type but not B-type lamins, while B-type lamins provide elasticity to the nucleus and the ability to deform. Thus, cells expressing very low levels of lamins A and C such as ESCs display a high degree of nuclear plasticity (Lammerding et al. 2006; Pajerowski et al. 2007). Accordingly, cells expressing high levels of lamins A and C have a high nuclear stiffness, which impairs the cells' ability to migrate through constraining micropores (Rowat et al. 2013; Shin et al. 2013; Harada et al. 2014).

\section{Lamins in signaling and gene expression}

Lamins affect a number of signaling pathways, some of which are tissue-specific (Heessen and Fornerod 2007; Andres and Gonzalez 2009). Their mode of action can be explained by forming a scaffolding structure that interacts with and regulates signaling molecules and transcription factors. On the one hand, lamins can attenuate signaling pathways by acting as a "peripheral nuclear trap" for transcriptional regulators, such as c-Fos and a transcriptional coactivator of the Notch pathway (SKIP) (Ivorra et al. 2006; Scaffidi and Misteli 2008). On the other hand, lamins can serve as a platform for signaling molecules, enabling efficient reactions. For example, phosphorylation of c-Fos by the extracellular signal-regulated kinase (ERK), both bound to lamins $\mathrm{A} / \mathrm{C}$, activates c-Fos/AP-1-driven transcription (Gonzalez et al. 2008). Furthermore, ERK-mediated displacement of retinoblastoma protein $(\mathrm{pRb})$ from lamins $\mathrm{A} / \mathrm{C}$ promotes its cdk-dependent phosphorylation (Rodriguez et al. 2010). Lamin scaffolds can also recruit nuclear phosphatase PP2A, promoting dephosphorylation of $\mathrm{pRb}$ (Van Berlo et al. 2005). In addition, lamins also indirectly affect signaling via the binding and regulation of integral proteins of the INM, such as emerin and MAN1 (Vaughan et al. 2001; Liu et al. 2003), which affect signaling pathways. MAN1 binds to and deactivates Smads, components of the transforming growth factor $\beta$ (TGF $\beta$ ) pathway (Lin et al. 2005), and emerin mediates nuclear export of $\beta$-catenin, a downstream factor of Wnt signaling (Markiewicz et al. 2006; Tilgner et al. 2009).

Interestingly, emerin has also been implicated in mechanosignaling. It was shown to exert capping activity toward pointed ends of actin filaments, thereby increasing actin polymerization (Holaska et al. 2004), which in turn regulates the mechanosensitive transcription factor megakaryoblastic leukemia 1 (MKL1), particularly in the cardiovascular system (Ho et al. 2013). MKL1 is a myocardin family member promoting up-regulation of serum response factor (SRF) genes, including actin and vinculin (Miralles et al. 2003). Binding of MKL1 to G-actin inhibits its nuclear import and promotes its nuclear export, 
thereby attenuating the SRF response (Mouilleron et al. 2008).

Besides lamins residing in the nuclear lamina, the nucleoplasmic A-type lamins (Dechat et al. 2010b) together with their binding partner, LAP2 $\alpha$ (Dechat et al. 2000), have also been implicated in signaling and gene expression. The lamin A/C-LAP2 $\alpha$ complex has been shown to regulate $\mathrm{pRb} / \mathrm{E} 2 \mathrm{~F}$ signaling (Markiewicz et al. 2002; Dorner et al. 2006; Pekovic et al. 2007) and thereby serves as key determinant of cell fate, keeping the wellbalanced state between proliferation and differentiation of tissue progenitor cells (Gesson et al. 2014). Loss of LAP2 $\alpha$ shifts this balance toward increased proliferation, potentiating the stemness character (Naetar et al. 2008; Gotic et al. 2010). Depletion of LAP2 $\alpha$ in mice causes selective loss of A-type lamins in the nucleoplasm, while Lmnadeficient mouse muscle cells up-regulate LAP $2 \alpha$ levels (Naetar et al. 2008; Cohen et al. 2013). Although our knowledge about the regulation and functions of nucleoplasmic lamins $\mathrm{A} / \mathrm{C}$ is still very sparse, it adds a completely new perspective to our current view on lamin A/C-mediated signaling.

Finally, aside from directly regulating components of cell signaling pathways, lamin complexes can also affect gene expression by organizing higher-order chromatin structure and regulating epigenetic pathways. Complexes of A-type lamins and the lamin B receptor (LBR), an integral INM protein, were shown to redundantly anchor heterochromatin to the lamina (Solovei et al. 2013). In addition, ablation of the single lamin gene in C. elegans or expression of a mutated muscle dystrophy-linked lamin was found to impair the tissue-specific regulation of the heterochromatin/lamina interaction during C. elegans development (Mattout et al. 2011). Genomic regions associated with the lamina, called lamina-associated domains (LADs), are up to $10 \mathrm{Mb}$ long, enriched in heterochromatic epigenetic marks, gene-poor, and transcriptionally inactive (Guelen et al. 2008; Peric-Hupkes et al. 2010). It has been proposed that lamina anchoring contributes to the stable silencing of genes during differentiation in a cell typespecific manner (Shevelyov et al. 2009; Meister et al. 2010; Towbin et al. 2010; Kohwi et al. 2013). A recent study showed that binding of lamin A to subregions in promoters influences gene expression dependent on the presence and localization of active and repressive histone marks within the promoter (Lund et al. 2013). However, the molecular mechanism underlying the regulation of gene expression by tethering chromatin to the lamina is still unclear. Interestingly, the binding of lamin A to promoters does not appear to be restricted to the nuclear periphery but occurs throughout the nuclear interior, involving nucleoplasmic lamin A complexes (Lund et al. 2013).

\section{The route and components of mechanosensing}

Mechanosensing defines the ability of cells to react to external forces such as stretch, shear stress, and compression, enabling them to sense and adapt to mechanical changes in their environment. Primary mechanosensors are located at the plasma membrane and can directly mediate the conversion of mechanical signals into biochemical signals (Fig. 1). Such sensors comprise integrins mediating cell attachment to the ECM, cell-cell adhesion molecules such as platelet endothelial cell adhesion molecule-1 (PECAM1), vascular endothelial growth factor receptor 2 (VEGFR2), mechanosensory complexes on endothelial cells such as VE cadherin (Fig. 2), and stretchactivatable ion channels (Tzima et al. 2005; Davies 2009; Wolfenson et al. 2013; Janostiak et al. 2014; Leckband and de Rooij 2014; Yao et al. 2014). Mechanostimulation usually results in stretching of the primary mechanosensor itself, unmasking cryptic binding sites for various molecules. For instance, stretching of integrins results in their conversion to a "high-affinity state," increasing the recruitment of focal adhesion (FA) components such as vinculin and activating a signaling cascade involving FA kinase
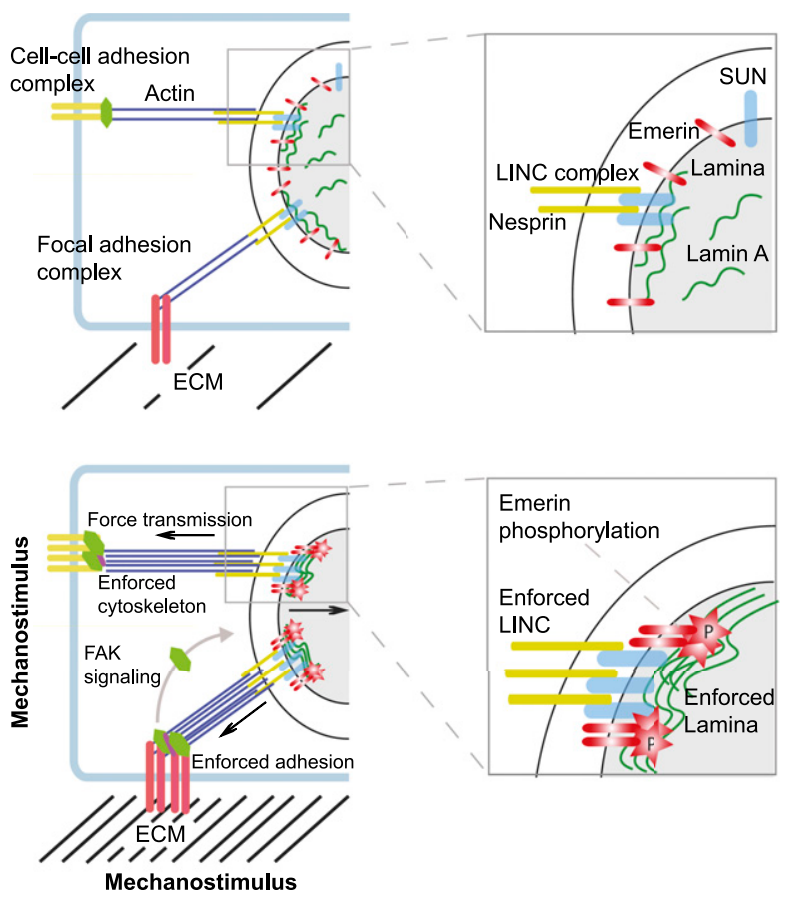

Figure 1. The route of mechanosensing and the tension-induced reinforcement response. (Top panels) Cell-cell adhesion and FA complexes that sense tension are physically linked to the nucleus via the cytoskeleton, LINC complexes (SUN and KASH domain proteins) in the nuclear membrane, and the nuclear lamina. Tension forces from the ECM are transmitted into the nucleus via these components and affect mechanoresponsive gene expression. (Bottom panels) In response to a mechanostimulus, such as increase in ECM stiffness, adhesion complexes, the actin cytoskeleton, LINC complexes, and the lamina are reinforced by the assembly of actin filaments, increased recruitment of adhesion complex and LINC complex proteins, and stabilization and assembly of A-type lamins at the lamina, thereby counteracting forces exerted from outside. In addition, the INM protein emerin becomes phosphorylated and contributes to LINC complex reinforcement. Tension also induces the activation of signaling cascades on adhesion complexes, such as FAK signaling, which affects mechanoresponsive gene expression without direct force transmission into the nucleus. Panels at the right depict higher-magnification views of the boxed areas in the nucleus shown in the left panels. 


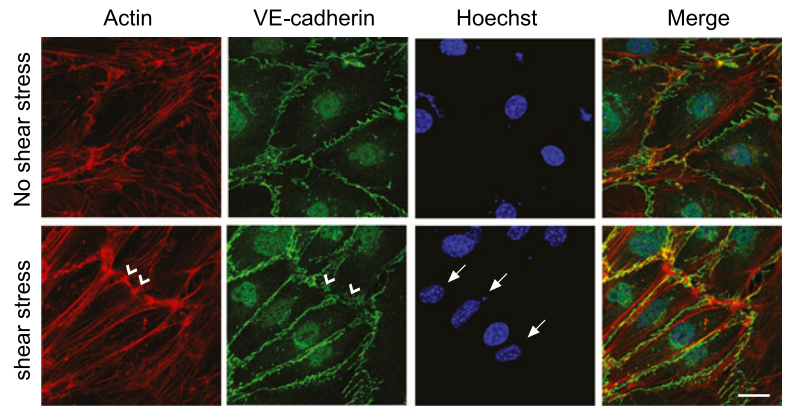

Figure 2. Shear stress force induces rearrangement of the cytoskeleton and cell alignment. Lung endothelial cells were exposed to flow shear stress $\left(12 \mathrm{dyn} / \mathrm{cm}^{2}\right)$ for $3 \mathrm{~h}$ and processed for immunofluorescence microscopy using actin and VE-cadherin antibodies. Hoechst was used for DNA staining. Shear stress induces increased alignment of actin stress fibers and elongation of nuclei (arrows) in the flow direction. Note "reinforcement" of cell-cell junctions particularly at the posterior and anterior ends of polarized cells as revealed by increased accumulation and "zipper-like" morphology of VE-cadherin junctions and increased cortical actin at these sites (arrowheads). Bar, $20 \mu \mathrm{m}$.

(FAK), Src, and ERK (Schwartz 2009). Prolonged mechanostimulation leads to long-term changes in gene expression, such as the up-regulation of endothelial nitrite oxide synthase (eNOS) in endothelial cells upon shear stress (Davis et al. 2004).

Many studies have emphasized the necessity of an intact cytoskeleton for the mechanoactivation of signaling molecules such as FAK and NFкB (Wang et al. 2009b). Davies (2009) proposes that efficient transmission of tension signals requires a well-interconnected and intact cytoskeleton. In support of this model, several studies have shown long-range cytoskeleton-mediated force propagation within the cytoplasm that can also be directly transmitted to the nucleus (Fig. 1; Maniotis et al. 1997; Hu et al. 2005; Wang et al. 2005). Similarly, the "hardwired" model proposes direct transmission of forces to the nucleus via integrins (Wang et al. 2009a). Consistent with this model, it has recently been shown by monitoring movements of fluorescently tagged nucleolar marker proteins that extracellular forces, such as compression and shear stress, can stimulate movements inside the nucleus, which, after prolonged exposure, are directly correlated in magnitude and direction to the applied stress (BoothGauthier et al. 2012). Thus, altering the mechanical environment of the cell can ultimately lead to long-term changes in nuclear organization and gene expression patterns. Altogether, activation of mechanoresponsive genes can be achieved via two main routes: one involving stretchinduced cell adhesion complex- and cytoskeleton-mediated activation of signaling molecules and transcriptional regulators at the plasma membrane and a second involving a direct force transmission into the nucleus (Fig. 1).

Direct force transmission into the nucleus requires intact physical connections of the nucleus to the cytoskeleton (Fig. 1). Such connections are mediated by the members of the so-called linker of nucleoskeleton and cytoskeleton (LINC) complex (Crisp et al. 2006; Tapley and Starr 2013). LINC complexes comprise SUN domain proteins that span the INM and are in the perinuclear space physically connected to nesprins, KASH domain proteins residing in the outer nuclear membrane (Sosa et al. 2012). Different types of nesprins either bind actin directly or interact via microtubule motor proteins and plectin with microtubules and IFs, respectively (Mejat and Misteli 2010). LINC components are crucial determinants of nuclear morphology, as nuclear height was shown to increase upon depletion of nesprin-1 in endothelial cells, presumably due to the lack of tensional forces exerted on the nucleus by actin cables (Chancellor et al. 2010). In support of their role in the direct transmission of forces to the nucleus, the nuclear deformation response to mechanical strain was found abrogated upon LINC disruption using dominant-negative SUN and nesprin constructs (Lombardi et al. 2011). Short-term activation of mechanosensitive genes, however, appeared unchanged in these LINC-disrupted cells. In contrast, activation of the wound healing response that requires activation of the mechanoresponsive signaling machinery was impaired in cells deficient for nesprin-2 (Rashmi et al. 2012), suggesting impaired mechanotransduction in these cells. Thus, it is still unclear to what extent LINC family members are essential for activation of mechanotransduction pathways.

LINC family members concentrate at specialized apical regions of the nucleus, the so-called transmembrane actin-associated nuclear (TAN) lines (Luxton et al. 2010). Sun-2 and Nesprin-2 giant are essential components of these TAN lines, which associate with dorsal actin cables at the cytoplasmic surface of the nucleus and are anchored via lamins to the nuclear interior. The INM proteins Samp and emerin (Borrego-Pinto et al. 2012; Chang et al. 2013) were also found in these complexes. TAN lines at the nuclear membrane resemble in many aspects FA complexes at the plasma membrane. Both are linked to actin fibers, and their formation is enhanced in response to increased contractility of the system upon serum stimulation or mechanostimulation, such as exposure to shear stress (Chambliss et al. 2013). Depletion of LINC complex components results in the inability of cells to respond to a shear stimulus and in defective cell polarization and migration (Luxton et al. 2010; Chambliss et al. 2013). Thus, TAN lines in analogy to FA sites represent major nuclear mechanosensing structures that are likely also involved in nuclear mechanotransduction (see below for possible mechanisms).

The most downstream components of the mechanosensing pathway from the ECM into the nucleus are the major nuclear mechanosensors, the A-type lamins (Fig. 1). It is their scaffolding property, as mentioned above, and their strategic position at the interface between LINC complexes in the nuclear membrane and chromatin that position them as key molecules of the nucleocytoskeletal coupling machinery. This notion is supported by studies showing that cells lacking A-type lamins or expressing lamin A mutants are unable to directly transmit forces to the nucleus (Poh et al. 2012; Zwerger et al. 2013) and that nuclei of these cells do not deform upon mechanostimuli 
(isotropic response) (Houben et al. 2007). In addition, the localization of various components of the LINC complex is severely disturbed in these cells (Hale et al. 2008; Chen et al. 2012, 2014), and the connection of the nuclei to TAN lines is weakened or lost (Folker et al. 2011). Importantly, this defective nucleocytoskeletal coupling appears to ultimately lead to defects in mechanotransduction, as reflected by the impaired activation of NFKB (Lammerding et al. 2004) and Yes-associated protein (YAP)/transcriptional coactivator with PDZ-binding motif (TAZ) (Swift et al. 2013; Bertrand et al. 2014) and MKL/SRF signaling (Ho et al. 2013).

\section{Molecular mechanisms of lamins in mechanosensing/signaling}

\section{'Outside-in signaling'}

The intriguing question arising at this point is how lamins propagate tensional forces to the nucleus. Recent data from the Disher laboratory (Swift et al. 2013) studying structural changes in lamin A upon mechanostimulation shed some light on this question (Fig. 3). Exposure of nuclei to shear stress induced stretching of lamin A filaments due to partial "unfolding" of the lamin Ig-fold. Interestingly, the Ig-fold in lamin A was recently shown to define the viscoelastic properties of lamin A and the mechanical resilience of lamin A networks (Bera et al. 2014).

Additional evidence for a structural and/or biochemical response of lamin A proteins to mechanical stimuli is demonstrated by dephosphorylation of lamin A at Ser22

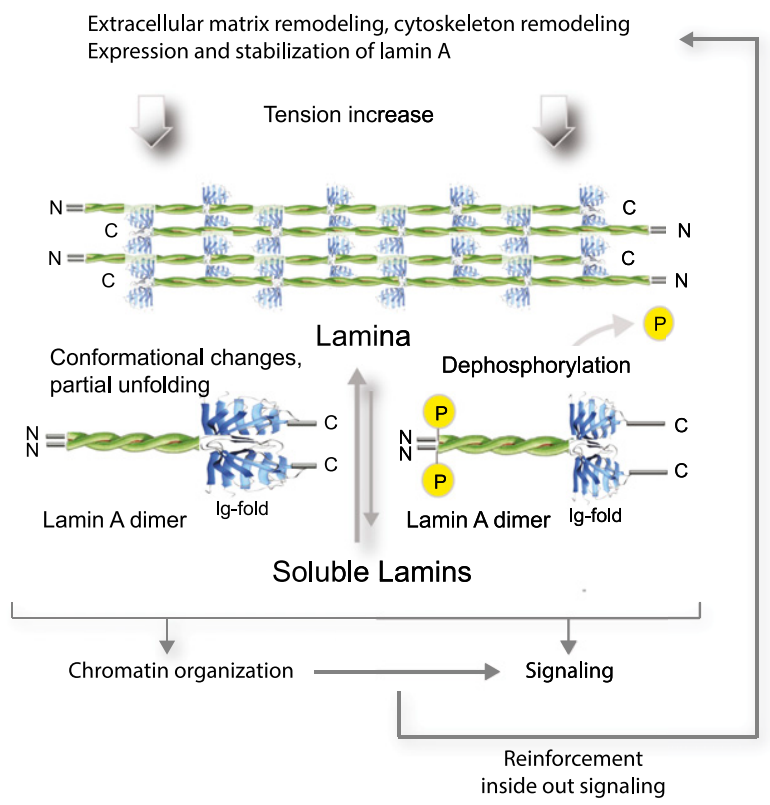

Figure 3. Lamin A in mechanosignaling. Increasing tension causes partial unfolding and dephosphorylation of lamin A as well as assembly of soluble lamin A into the lamina. These structural and biochemical changes of the protein may affect chromatin organization and cell signaling, thereby activating the reinforcement response, including increased lamin A expression and remodeling of the cytoskeleton and the ECM. and Ser390 upon increased matrix stiffness and cell tension (Buxboim et al. 2014). Lamin phosphorylation at these sites is required for mitotic lamina disassembly (Heald and McKeon 1990) and promotes dissociation of lamin A from the lamina and distribution throughout the nucleus in interphase cells (Kochin et al. 2014). Therefore, it was proposed that stress-mediated changes in lamin A/C phosphorylation at these sites may regulate lamin A assembly into the lamina and its stability (Buxboim et al. 2014). In this model, increased tension would favor dephosphorylation of lamins, leading to its assembly into the lamina and an increase in protein stability (Fig. 3). How mechanical tension affects lamin A phosphorylation is still unclear, but it is conceivable that the degree of lamin stretching may affect phosphorylation and/or dephosphorylation by changing the access for kinases or phosphatases. In line with this, Swift et al. (2013) have shown that a lamin A protein with a muscular dystrophy-causing alteration in the Ig-fold (R453W) is less phosphorylated and that this is correlated with an apparently higher degree of protein unfolding. It must be emphasized though that our knowledge of tensional changes in lamins and consequences of such alterations for the protein and the cell is still sparse and requires further elucidation.

Regardless of the exact mode of action, "stretched lamins" could further relay the tensional input to the nuclear interior by the following not mutually exclusive mechanisms (Fig. 3; Isermann and Lammerding 2013): Changes in the mechanical properties of A-type lamins and the lamina may (1) alter chromatin organization and accessibility for chromatin regulators, (2) cause chromatin detachment from the transcriptionally repressive periphery, and (3) alter the interaction of signaling molecules with A-type lamins. This model is particularly intriguing in view of the emerging concept that both A-type lamins associated with the peripheral lamina and A-type lamins in the nuclear interior affect chromatin organization, signaling, and gene expression (Dechat et al. 2010b). Thus, changes in the ratio of lamina-associated versus nucleoplasmic pools of lamins A/C may significantly affect the cellular phenotype.

Recent data on isolated nuclei have shown that lamin A also mediates the tension-mediated nuclear stiffening response (Fig. 1). Using magnetic tweezers to apply forces on nesprins in isolated nuclei resulted in higher nuclear stiffness through increased recruitment of lamins to LINC complexes (Guilluy et al. 2014). These forces also induced emerin phosphorylation, which appears to act as tension sensor. In the absence of lamins, nuclei exhibit a reduced resistance to forces and cannot respond to tension by nuclear stiffening. In line with such a mechanism, nuclei lacking functional lamin A/C or emerin are unable to resist forces exerted by TAN lines despite unperturbed assembly of Sun and Nesprin-2 giant (Folker et al. 2011; Chang et al. 2013). In these cells, TAN lines were found to slip over nuclei rather than move with them.

Such tension-mediated reinforcement mechanisms were long known to operate at the "cytoplasmic" level. ECM-exerted forces on integrins induce assembly and 
phosphorylation of FA components and increased actindriven contractility that in turn promote ECM assembly in a feedback loop (Fig. 2; Galbraith et al. 2002; IcardArcizet et al. 2008; Schwartz 2009; Humphrey et al. 2014). It still awaits to be seen whether, similar to FAs, "nuclear adhesion" also involves a plethora of other components besides emerin and whether these can directly signal to actin filaments. This is supported by the observation that cells expressing emerin phosphorylation mutants exhibited a significant reduction in actin stress fibers (Guilluy et al. 2014).

\section{'Inside-out' signaling}

Recent findings from the Discher laboratory (Swift et al. 2013; Buxboim et al. 2014) show that cells not only adjust to increased forces by reinforcing the coupling of lamins to LINC complexes but also increase lamin A protein levels in response to force. Tension exerted through myosin-mediated actin stress fiber assembly following plating of cells on a stiff matrix promotes dephosphorylation and stabilization of the lamin A protein within $30 \mathrm{~min}$. Longterm responses and adjustment to increased matrix stiffness, as occurs during osteogenic differentiation, require several days and involve increased expression of the lamin A gene. Increased tension also leads to the up-regulation of the mechanosensitive SRF pathway that in turn upregulates myosin IIA. This so called "mechanobiological gene circuit" is a feedback loop to increase tension in the cell. It requires intact nucleocytoskeletal mechanocoupling, as disruption of the LINC complex and the actin cytoskeleton perturbs such a circuit.

Very little is known about the exciting features of lamin A-mediated inside-out signaling, but a few potential mechanisms are emerging: A-type lamins are required for the correct localization of emerin in the INM (Sullivan et al. 1999), which regulates actin assembly (Holaska et al. 2004) and the mechanosensitive MKL1SRF pathway (Ho et al. 2013). In addition, emerin is known to affect wnt signaling (Markiewicz et al. 2006), which in turn regulates expression of ECM components (Hernandez et al. 2010). In line with this model, a growing amount of data shows that mutations in A-type lamins affect the composition of the ECM. Lamin A/C-deficient fibroblasts exhibited increased collagen synthesis, and, importantly, re-expression of lamins $\mathrm{A} / \mathrm{C}$ reverted this phenotype (Van Berlo et al. 2005). In addition, HGPS patient cells expressing progerin and ZMPSTE24-deficient mice expressing prelamin A (Hernandez et al. 2010; de la Rosa et al. 2013) showed aberrant ECM production. In particular, proteoglycans (Beavan et al. 1993), glycoproteins, and collagen XI that regulate collagen assembly (Hernandez et al. 2010) and many other ECM components (Csoka et al. 2004) were affected. Interestingly, these changes were linked to altered TGF- $\beta$ signaling in $\mathrm{Lmna}^{-1-}$ cells and wnt $/ \beta$-catenin signaling in HGPS cells (Van Berlo et al. 2005; Hernandez et al. 2010). While it is well known that Rho-activated cell contractility and tension modulate the expression of ECM components in a TGF- $\beta$-dependent manner (Chapados et al. 2006; Marenzana et al. 2006; Meyer-ter-Vehn et al. 2006), the role of A-type lamins in this "mechanobiological gene circuit" is still unclear (Buxboim et al. 2014).

Another potential mechanism as to how tensioninduced changes in lamin A protein levels and localization may affect gene expression comes from recent studies showing that binding of lamin A to promoters may regulate gene expression during adipocyte differentiation (Lund et al. 2013).

\section{Lamin A in cell migration}

Activation of Rho-GTPases is one of the primary cellular responses to mechanical stimuli that leads to extensive cytoskeletal rearrangement, cell polarization, and migration (Houben et al. 2007). During wound healing-induced migration, cytoskeletal remodeling is accompanied by increased attachment of actin stress fibers to nuclear TAN lines and dorsal movements of actin cables dragging nuclei away from the wound edge. At the same time, repositioning of the centrosome toward the leading edge occurs. Atype lamins appear essential for these processes, since, in their absence, cells fail to reposition their nuclei, and centrosomes fail to polarize (Luxton et al. 2010; Folker et al. 2011). However, nuclear repositioning does not appear crucial for the overall two-dimensional (2D) cell migration, since lamin A deficiency results only in a mild reduction in migration speed (Hale et al. 2008). In contrast, migration through a constrictive micrometer-scale pore three-dimensional (3D) environment is significantly delayed in cancer cells or neutrophils with high lamin A levels. This is conceivable since A-type lamins affect nuclear morphology and its visco-elastic properties, increasing nuclear stiffness (see above) and thus allowing only limited compressibility. Consistent with this notion, HGPS cells with increased nuclear stiffness (Dahl et al. 2006) show slowed down migration through 6- $\mu \mathrm{m}$-thick constrictions (BoothGauthier et al. 2013), whereas lamin A knockdown increased the migration speed through constrictions but reduced overall resistance of cells to stress (Harada et al. 2014).

\section{Role of lamin-mediated mechanosensing in disease}

Mutations in the LMNA gene cause $\sim 14$ different diseases termed laminopathies (Worman 2012). The majority of disease-causing mutations in $L M N A$ are autosomal dominant missense mutations, leading to a single amino acid change in lamins A and C. Depending on the localization in the gene, these mutations can interfere with protein folding (Bollati et al. 2012), stability, and assembly (Wiesel et al. 2008; Bank et al. 2012) or change the biochemical properties of the protein (Krimm et al. 2002). Most of the HGPS cases are caused by a silent mutation in $L M N A$, leading to missplicing of the $L M N A$ transcript and production of a slightly smaller form of lamin A that, unlike wild-type lamin A, maintains its farnesylated and carboxymethylated C-terminal cysteine (Worman 2012).

In the context of mechanosensing, mutations affecting mechanical load-bearing tissues are of particular interest, 
such as striated muscle in EDMD and DCM and smooth muscle and cartilage/bone in accelerating aging disorders. Interestingly, similar disease phenotypes like in LMNAlinked EDMD and DCM can also be observed by mutations in $E M D$ (encoding emerin) and in genes encoding LINC complex family members, such as SYNE1 and SYNE2 (encoding nesprin-1 and nesprin-2) and SUN1 and SUN2 (encoding SUNs) (Schreiber and Kennedy 2013; Meinke et al. 2014). These data strongly suggest that defective nucleocytoskeletal coupling is a major cause for the disease phenotypes in muscle. In line with this model, cells harboring these myopathic lamin mutations had impaired nuclear stability and defective nuclear force transmission (Folker et al. 2011; Zwerger et al. 2013). Myopathic lamin mutations but not those causing phenotypes in adipose tissues also caused defective TAN line anchoring (Folker et al. 2011). Furthermore, lamin A/C-deficient mice, characterized by severe DCM, show absence of desmin attachments to the nucleus in cardiomyocytes and did not develop a "hypertrophic mechanoresponse" (Nikolova et al. 2004).

Similarly, HGPS-linked defects in mechanical loadbearing tissues, such as smooth muscle and bone, may be caused by aberrant nucleocytoskeletal coupling. In accordance with this, accumulation of progerin was shown to cause disturbances in LINC complexes. For instance, farnesylated lamin (prelamin and progerin) showed increased affinity for SUN proteins, thereby reducing their mobility (Chen et al. 2014). Interestingly, deletion of SUN1 in both $\mathrm{Lmna}^{-1-}$ mice and a progeria mouse model ameliorated the disease phenotypes (Chen et al. 2012; Suh and Kennedy 2012). Progerin/prelamin also showed increased binding to emerin, and prelamin expression strongly influenced the localization of emerin (Capanni et al. 2009; Wu et al. 2014).

As mentioned above, one of the possible consequences of disturbed mechanocoupling is the altered expression of ECM components. This is particularly relevant in view of the fact that the hallmark of many laminopathies is increased fibrosis (increased collagen production) (Reichel and Garcia-Bunuel 1970; Van Berlo et al. 2005; Worman 2012). DCM is very often associated with increased expression of $T g f b 1 / T g f b 2$ and Col1a genes (Margulies et al. 2009). Furthermore, cardiovascular pathology in HGPS was characterized by very pronounced collagen accumulation, which leads to severe atherosclerosis, myocardial infarction, and stroke at a very early age (Olive et al. 2010). Thus, it is conceivable that the accelerated aging process in HGPS is partially caused by dysfunctional ECM production. The aging process itself has been associated with defective ECM production. For example, the reduced self-renewal and bone formation capacity of aged mesenchymal stem cells (MSCs) was corrected by culturing them on ECM from young MSCs (Sun et al. 2011). In analogy to that, proliferative defects of mouse adult fibroblasts harboring HGPS-linked Lmna mutation were rescued upon growth on ECM derived from wild-type cells (Hernandez et al. 2010). Similar observations were reported for Zmpste24 ${ }^{-/-}$cells (de la Rosa et al. 2013). This study also showed that, in contrast to the severely reduced life span in mice completely lacking ZMPSTE24, the ZMPSTE24 mosaic mice containing equal numbers of ZMPSTE-deficient (prelamin Aaccumulating) and ZMPSTE-proficient (mature Lamin A-containing) cells in the tissues develop normally. Altogether a "well-balanced relationship" between the nuclear lamina and the extracellular environment may be a key factor toward a delayed aging response.

\section{Acknowledgments}

Work in our laboratory is supported by grants from the Austrian Science Fund to R.F. (FWF grant P26492-B20) and S.O.-M. (Hertha-Firnberg fellowship FWF $\mathrm{T}$ 584-B23) and from the Herzfelder'sche Familienstiftung, and an Innovator Award from the Progeria Research Foundation (PRF2011-37) to T.D.

\section{References}

Aebi U, Cohn J, Buhle L, Gerace L. 1986. The nuclear lamina is a meshwork of intermediate-type filaments. Nature 323: 560564.

Andres V, Gonzalez JM. 2009. Role of A-type lamins in signaling, transcription, and chromatin organization. J Cell Biol 187: 945957.

Bank EM, Ben-Harush K, Feinstein N, Medalia O, Gruenbaum Y. 2012. Structural and physiological phenotypes of disease-linked lamin mutations in C. elegans. J Struct Biol 177: 106-112.

Barrowman J, Hamblet C, George CM, Michaelis S. 2008. Analysis of prelamin A biogenesis reveals the nucleus to be a CaaX processing compartment. Mol Biol Cell 19: 5398-5408.

Beavan LA, Quentin-Hoffmann E, Schonherr E, Snigula F, Leroy JG, Kresse H. 1993. Deficient expression of decorin in infantile progeroid patients. J Biol Chem 268: 9856-9862.

Ben-Harush K, Wiesel N, Frenkiel-Krispin D, Moeller D, Soreq E, Aebi U, Herrmann H, Gruenbaum Y, Medalia O. 2009. The supramolecular organization of the C. elegans nuclear lamin filament. J Mol Biol 386: 1392-1402.

Bera M, Kotamarthi HC, Dutta S, Ray A, Ghosh S, Bhattacharyya D, Ainavarapu SR, Sengupta K. 2014. Characterization of unfolding mechanism of human lamin A Ig fold by single-molecule force spectroscopy-implications in EDMD. Biochemistry 25: 7247-7258.

Bergo MO, Gavino B, Ross J, Schmidt WK, Hong C, Kendall LV, Mohr A, Meta M, Genant H, Jiang Y, et al. 2002. Zmpste24 deficiency in mice causes spontaneous bone fractures, muscle weakness, and a prelamin A processing defect. Proc Natl Acad Sci 99: 13049-13054.

Bertrand AT, Ziaei S, Ehret C, Duchemin H, Mamchaoui K, Bigot A, Mayer M, Quijano-Roy S, Desguerre I, Laine J, et al. 2014. Cellular microenvironments reveal defective mechanosensing responses and elevated YAP signaling in LMNAmutated muscle precursors. I Cell Sci 127: 2873-2884.

Bollati M, Barbiroli A, Favalli V, Arbustini E, Charron P, Bolognesi M. 2012. Structures of the lamin A/C R335W and E347K mutants: implications for dilated cardiolaminopathies. Biochem Biophys Res Commun 418: 217-221.

Booth-Gauthier EA, Alcoser TA, Yang G, Dahl KN. 2012. Forceinduced changes in subnuclear movement and rheology. Biophys J 103: 2423-2431.

Booth-Gauthier EA, Du V, Ghibaudo M, Rape AD, Dahl KN, Ladoux B. 2013. Hutchinson-Gilford progeria syndrome alters nuclear shape and reduces cell motility in three dimensional model substrates. Integr Biol (Camb) 5: 569-577.

Borrego-Pinto J, Jegou T, Osorio DS, Aurade F, Gorjanacz M, Koch B, Mattaj IW, Gomes ER. 2012. Samp1 is a component 
of TAN lines and is required for nuclear movement. / Cell Sci 125: 1099-1105.

Broers JL, Peeters EA, Kuijpers HJ, Endert J, Bouten CV, Oomens CW, Baaijens FP, Ramaekers FC. 2004. Decreased mechanical stiffness in $\mathrm{LMNA}^{-1-}$ cells is caused by defective nucleocytoskeletal integrity: implications for the development of laminopathies. Hum Mol Genet 13: 2567-2580.

Burke B, Stewart CL. 2013. The nuclear lamins: flexibility in function. Nat Rev Mol Cell Biol 14: 13-24.

Burke B, Stewart CL. 2014. Functional architecture of the cell's nucleus in development, aging, and disease. Curr Top Dev Biol 109: 1-52.

Buxboim A, Swift J, Irianto J, Spinler KR, Dingal PC, Athirasala A, Kao YR, Cho S, Harada T, Shin JW, et al. 2014. Matrix elasticity regulates lamin-A,C phosphorylation and turnover with feedback to actomyosin. Curr Biol 24: 1909-1917.

Capanni C, Del Coco R, Mattioli E, Camozzi D, Columbaro M, Schena E, Merlini L, Squarzoni S, Maraldi NM, Lattanzi G. 2009. Emerin-prelamin A interplay in human fibroblasts. Biol Cell 101: 541-554.

Carboni N, Politano L, Floris M, Mateddu A, Solla E, Olla S, Maggi L, Antonietta Maioli M, Piras R, Cocco E et al. 2013. Overlapping syndromes in laminopathies: a meta-analysis of the reported literature. Acta Myol 32: 7-17.

Cenni V, Sabatelli P, Mattioli E, Marmiroli S, Capanni C, Ognibene A, Squarzoni S, Maraldi NM, Bonne G, Columbaro $\mathrm{M}$, et al. 2005. Lamin A N-terminal phosphorylation is associated with myoblast activation: impairment in EmeryDreifuss muscular dystrophy. I Med Genet 42: 214-220.

Chambliss AB, Khatau SB, Erdenberger N, Robinson DK, Hodzic D, Longmore GD, Wirtz D. 2013. The LINC-anchored actin cap connects the extracellular milieu to the nucleus for ultrafast mechanotransduction. Sci Rep 3: 1087.

Chancellor TJ, Lee J, Thodeti CK, Lele T. 2010. Actomyosin tension exerted on the nucleus through nesprin-1 connections influences endothelial cell adhesion, migration, and cyclic strain-induced reorientation. Biophys J 99: 115-123.

Chang W, Folker ES, Worman HJ, Gundersen GG. 2013. Emerin organizes actin flow for nuclear movement and centrosome orientation in migrating fibroblasts. Mol Biol Cell 24: 38693880.

Chapados R, Abe K, Ihida-Stansbury K, McKean D, Gates AT, Kern M, Merklinger S, Elliott J, Plant A, Shimokawa H, et al. 2006. ROCK controls matrix synthesis in vascular smooth muscle cells: coupling vasoconstriction to vascular remodeling. Circ Res 99: 837-844.

Chen CY, Chi YH, Mutalif RA, Starost MF, Myers TG, Anderson SA, Stewart CL, Jeang KT. 2012. Accumulation of the inner nuclear envelope protein Sun1 is pathogenic in progeric and dystrophic laminopathies. Cell 149: 565-577.

Chen ZJ, Wang WP, Chen YC, Wang JY, Lin WH, Tai LA, Liou GG, Yang CS, Chi YH. 2014. Dysregulated interactions between lamin A and SUN1 induce abnormalities in the nuclear envelope and endoplasmic reticulum in progeric laminopathies. J Cell Sci 127: 1792-1804.

Choi JC, Worman HJ. 2014. Nuclear envelope regulation of signaling cascades. Adv Exp Med Biol 773: 187-206.

Coffinier C, Chang SY, Nobumori C, Tu Y, Farber EA, Toth II, Fong LG, Young SG. 2010. Abnormal development of the cerebral cortex and cerebellum in the setting of lamin B2 deficiency. Proc Natl Acad Sci 107: 5076-5081.

Coffinier C, Jung HJ, Nobumori C, Chang S, Tu Y, Barnes RH 2nd, Yoshinaga Y, de Jong PJ, Vergnes L, Reue K, et al. 2011. Deficiencies in lamin B1 and lamin B2 cause neurodevelopmental defects and distinct nuclear shape abnormalities in neurons. Mol Biol Cell 22: 4683-4693.
Cohen M, Lee KK, Wilson KL, Gruenbaum Y. 2001. Transcriptional repression, apoptosis, human disease and the functional evolution of the nuclear lamina. Trends Biochem Sci 26: $41-47$.

Cohen TV, Gnocchi VF, Cohen JE, Phadke A, Liu H, Ellis JA, Foisner R, Stewart CL, Zammit PS, Partridge TA. 2013. Defective skeletal muscle growth in lamin A/C-deficient mice is rescued by loss of Lap2 $\alpha$. Hum Mol Genet 22: 28522869.

Collas P. 1999. Sequential PKC- and Cdc2-mediated phosphorylation events elicit zebrafish nuclear envelope disassembly. J Cell Sci 112: 977-987.

Collas P, Lund EG, Oldenburg AR. 2014. Closing the (nuclear) envelope on the genome: how nuclear lamins interact with promoters and modulate gene expression. BioEssays 36: 75-83.

Corrigan DP, Kuszczak D, Rusinol AE, Thewke DP, Hrycyna CA, Michaelis S, Sinensky MS. 2005. Prelamin A endoproteolytic processing in vitro by recombinant Zmpste24. Biochem I 387: 129-138.

Crisp M, Liu Q, Roux K, Rattner JB, Shanahan C, Burke B, Stahl PD, Hodzic D. 2006. Coupling of the nucleus and cytoplasm: role of the LINC complex. J Cell Biol 172: 41-53.

Csoka AB, English SB, Simkevich CP, Ginzinger DG, Butte AJ, Schatten GP, Rothman FG, Sedivy JM. 2004. Genome-scale expression profiling of Hutchinson-Gilford progeria syndrome reveals widespread transcriptional misregulation leading to mesodermal/mesenchymal defects and accelerated atherosclerosis. Aging Cell 3: 235-243.

Dahl KN, Kahn SM, Wilson KL, Discher DE. 2004. The nuclear envelope lamina network has elasticity and a compressibility limit suggestive of a molecular shock absorber. J Cell Sci 117: 4779-4786.

Dahl KN, Engler AJ, Pajerowski JD, Discher DE. 2005. Powerlaw rheology of isolated nuclei with deformation mapping of nuclear substructures. Biophys J 89: 2855-2864.

Dahl KN, Scaffidi P, Islam MF, Yodh AG, Wilson KL, Misteli T. 2006. Distinct structural and mechanical properties of the nuclear lamina in Hutchinson-Gilford progeria syndrome. Proc Natl Acad Sci 103: 10271-10276.

Davies PF. 2009. Hemodynamic shear stress and the endothelium in cardiovascular pathophysiology. Nat Clin Pract Cardiovasc Med 6: 16-26.

Davis ME, Grumbach IM, Fukai T, Cutchins A, Harrison DG. 2004. Shear stress regulates endothelial nitric-oxide synthase promoter activity through nuclear factor $\kappa \mathrm{B}$ binding. I Biol Chem 279: 163-168.

Dechat T, Korbei B, Vaughan OA, Vlcek S, Hutchison CJ, Foisner R. 2000. Lamina-associated polypeptide $2 \alpha$ binds intranuclear A-type lamins. J Cell Sci 113: 3473-3484.

Dechat T, Gajewski A, Korbei B, Gerlich D, Daigle N, Haraguchi T, Furukawa K, Ellenberg J, Foisner R. 2004. LAP2 $\alpha$ and BAF transiently localize to telomeres and specific regions on chromatin during nuclear assembly. J Cell Sci 117: 6117-6128.

Dechat T, Shimi T, Adam SA, Rusinol AE, Andres DA, Spielmann HP, Sinensky MS, Goldman RD. 2007. Alterations in mitosis and cell cycle progression caused by a mutant lamin A known to accelerate human aging. Proc Natl Acad Sci 104: 4955-4960.

Dechat T, Pfleghaar K, Sengupta K, Shimi T, Shumaker DK, Solimando L, Goldman RD. 2008. Nuclear lamins: major factors in the structural organization and function of the nucleus and chromatin. Genes Dev 22: 832-853.

Dechat T, Adam SA, Taimen P, Shimi T, Goldman RD. 2010a. Nuclear lamins. Cold Spring Harb Perspect Biol 2: a000547.

Dechat T, Gesson K, Foisner R. 2010b. Lamina-independent lamins in the nuclear interior serve important functions. Cold Spring Harb Symp Quant Biol 75: 533-543. 
de la Rosa J, Freije JM, Cabanillas R, Osorio FG, Fraga MF, Fernandez-Garcia MS, Rad R, Fanjul V, Ugalde AP, Liang Q, et al. 2013. Prelamin A causes progeria through cell-extrinsic mechanisms and prevents cancer invasion. Nat Commun 4: 2268.

Dessev GN, Iovcheva-Dessev C, Goldman RD. 1990. Lamin dimers. Presence in the nuclear lamina of surf clam oocytes and release during nuclear envelope breakdown. I Biol Chem 265: 12636-12641.

Dhe-Paganon S, Werner ED, Chi YI, Shoelson SE. 2002. Structure of the globular tail of nuclear lamin. I Biol Chem 277: 17381-17384.

Dorner D, Vlcek S, Foeger N, Gajewski A, Makolm C, Gotzmann J, Hutchison CJ, Foisner R. 2006. Lamina-associated polypeptide $2 \alpha$ regulates cell cycle progression and differentiation via the retinoblastoma-E2F pathway. J Cell Biol 173: 83-93.

Eckersley-Maslin MA, Bergmann JH, Lazar Z, Spector DL. 2013. Lamin $\mathrm{A} / \mathrm{C}$ is expressed in pluripotent mouse embryonic stem cells. Nucleus 4: 53-60.

Fedorchak GR, Kaminski A, Lammerding J. 2014. Cellular mechanosensing: getting to the nucleus of it all. Prog Biophys Mol Biol 115: 76-92.

Foeger N, Wiesel N, Lotsch D, Mucke N, Kreplak L, Aebi U, Gruenbaum Y, Herrmann H. 2006. Solubility properties and specific assembly pathways of the B-type lamin from Caenorhabditis elegans. J Struct Biol 155: 340-350.

Folker ES, Ostlund C, Luxton GW, Worman HJ, Gundersen GG. 2011. Lamin A variants that cause striated muscle disease are defective in anchoring transmembrane actin-associated nuclear lines for nuclear movement. Proc Natl Acad Sci 108: 131-136.

Galbraith CG, Yamada KM, Sheetz MP. 2002. The relationship between force and focal complex development. I Cell Biol 159: 695-705.

Gerace L, Blobel G. 1980. The nuclear envelope lamina is reversibly depolymerized during mitosis. Cell 19: 277-287.

Gesson K, Vidak S, Foisner R. 2014. Lamina-associated polypeptide (LAP) $2 \alpha$ and nucleoplasmic lamins in adult stem cell regulation and disease. Semin Cell Dev Biol 29: 116-124.

Gieffers C, Krohne G. 1991. In vitro reconstitution of recombinant lamin A and a lamin A mutant lacking the carboxyterminal tail. Eur J Cell Biol 55: 191-199.

Goldberg MW, Huttenlauch I, Hutchison CJ, Stick R. 2008. Filaments made from A- and B-type lamins differ in structure and organization. J Cell Sci 121: 215-225.

Gonzalez JM, Navarro-Puche A, Casar B, Crespo P, Andres V. 2008. Fast regulation of AP-1 activity through interaction of lamin A/C, ERK1/2, and c-Fos at the nuclear envelope. J Cell Biol 183: 653-666.

Gotic I, Schmidt WM, Biadasiewicz K, Leschnik M, Spilka R, Braun J, Stewart CL, Foisner R. 2010. Loss of LAP2 $\alpha$ delays satellite cell differentiation and affects postnatal fiber-type determination. Stem Cells 28: 480-488.

Grossman E, Dahan I, Stick R, Goldberg MW, Gruenbaum Y, Medalia O. 2012. Filaments assembly of ectopically expressed Caenorhabditis elegans lamin within Xenopus oocytes. I Struct Biol 177: 113-118.

Guelen L, Pagie L, Brasset E, Meuleman W, Faza MB, Talhout W, Eussen $\mathrm{BH}$, de Klein A, Wessels L, de Laat W, et al. 2008. Domain organization of human chromosomes revealed by mapping of nuclear lamina interactions. Nature 453: 948951.

Guilluy C, Osborne LD, Van Landeghem L, Sharek L, Superfine R, Garcia-Mata R, Burridge K. 2014. Isolated nuclei adapt to force and reveal a mechanotransduction pathway in the nucleus. Nat Cell Biol 16: 376-381.
Guo Y, Kim Y, Shimi T, Goldman RD, Zheng Y. 2014. Concentration-dependent lamin assembly and its roles in the localization of other nuclear proteins. Mol Biol Cell 25: 1287-1297.

Hale CM, Shrestha AL, Khatau SB, Stewart-Hutchinson PJ, Hernandez L, Stewart CL, Hodzic D, Wirtz D. 2008. Dysfunctional connections between the nucleus and the actin and microtubule networks in laminopathic models. Biophys J 95: 5462-5475.

Harada T, Swift J, Irianto J, Shin JW, Spinler KR, Athirasala A, Diegmiller R, Dingal PC, Ivanovska IL, Discher DE. 2014. Nuclear lamin stiffness is a barrier to $3 \mathrm{D}$ migration, but softness can limit survival. J Cell Biol 204: 669-682.

Heald R, McKeon F. 1990. Mutations of phosphorylation sites in lamin A that prevent nuclear lamina disassembly in mitosis. Cell 61: 579-589.

Heessen S, Fornerod M. 2007. The inner nuclear envelope as a transcription factor resting place. EMBO Rep 8: 914-919.

Heitlinger E, Peter M, Haner M, Lustig A, Aebi U, Nigg EA. 1991. Expression of chicken lamin B2 in Escherichia coli: characterization of its structure, assembly, and molecular interactions. J Cell Biol 113: 485-495.

Hennekes H, Peter M, Weber K, Nigg EA. 1993. Phosphorylation on protein kinase $\mathrm{C}$ sites inhibits nuclear import of lamin B2. J Cell Biol 120: 1293-1304.

Hernandez L, Roux KJ, Wong ES, Mounkes LC, Mutalif R, Navasankari R, Rai B, Cool S, Jeong JW, Wang H, et al. 2010. Functional coupling between the extracellular matrix and nuclear lamina by Wnt signaling in progeria. Dev Cell 19: 413-425.

Ho CY, Jaalouk DE, Vartiainen MK, Lammerding J. 2013. Lamin $\mathrm{A} / \mathrm{C}$ and emerin regulate MKL1-SRF activity by modulating actin dynamics. Nature 497: 507-511.

Holaska JM, Kowalski AK, Wilson KL. 2004. Emerin caps the pointed end of actin filaments: evidence for an actin cortical network at the nuclear inner membrane. PLoS Biol 2: E231.

Houben F, Ramaekers FC, Snoeckx LH, Broers JL. 2007. Role of nuclear lamina-cytoskeleton interactions in the maintenance of cellular strength. Biochim Biophys Acta 1773: 675-686.

Hu S, Chen J, Butler JP, Wang N. 2005. Prestress mediates force propagation into the nucleus. Biochem Biophys Res Commun 329: 423-428.

Humphrey JD, Dufresne ER, Schwartz MA. 2014. Mechanotransduction and extracellular matrix homeostasis. Nat ReV Mol Biol 15: 802-812.

Icard-Arcizet D, Cardoso O, Richert A, Henon S. 2008. Cell stiffening in response to external stress is correlated to actin recruitment. Biophys J 94: 2906-2913.

Isermann P, Lammerding J. 2013. Nuclear mechanics and mechanotransduction in health and disease. Curr Biol 23: R1113-R1121.

Ito H, Koyama Y, Takano M, Ishii K, Maeno M, Furukawa K, Horigome T. 2007. Nuclear envelope precursor vesicle targeting to chromatin is stimulated by protein phosphatase 1 in Xenopus egg extracts. Exp Cell Res 313: 1897-1910.

Ivorra C, Kubicek M, Gonzalez JM, Sanz-Gonzalez SM, AlvarezBarrientos A, O'Connor JE, Burke B, Andres V. 2006. A mechanism of AP-1 suppression through interaction of cFos with lamin A/C. Genes Dev 20: 307-320.

Janostiak R, Pataki AC, Brabek J, Rosel D. 2014. Mechanosensors in integrin signaling: the emerging role of p130Cas. Eur $J$ Cell Biol 10-12: 445-454.

Jung HJ, Tatar A, Tu Y, Nobumori C, Yang SH, Goulbourne CN, Herrmann H, Fong LG, Young SG. 2014. An absence of nuclear lamins in keratinocytes leads to ichthyosis, defective epidermal barrier function, and intrusion of nuclear membranes and endoplasmic reticulum into the nuclear chromatin. Mol Cell Biol 34: 4534-4544. 
Kalinowski A, Qin Z, Coffey K, Kodali R, Buehler MJ, Losche M, Dahl KN. 2013. Calcium causes a conformational change in lamin A tail domain that promotes farnesyl-mediated membrane association. Biophys J 104: 2246-2253.

Karabinos A, Schunemann J, Meyer M, Aebi U, Weber K. 2003. The single nuclear lamin of Caenorhabditis elegans forms in vitro stable intermediate filaments and paracrystals with a reduced axial periodicity. J Mol Biol 325: 241-247.

Kennedy BK, Pennypacker JK. 2014. RB and lamins in cell cycle regulation and aging. Adv Exp Med Biol 773: 127-142.

Kim Y, Zheng Y. 2013. Generation and characterization of a conditional deletion allele for Lmna in mice. Biochem Biophys Res Commun 440: 8-13.

Kim Y, Sharov AA, McDole K, Cheng M, Hao H, Fan CM, Gaiano N, Ko MS, Zheng Y. 2011. Mouse B-type lamins are required for proper organogenesis but not by embryonic stem cells. Science 334: 1706-1710.

Kim Y, Zheng X, Zheng Y. 2013. Proliferation and differentiation of mouse embryonic stem cells lacking all lamins. Cell Res 23: 1420-1423.

Kochin V, Shimi T, Torvaldson E, Adam SA, Goldman A, Pack CG, Melo-Cardenas J, Imanishi SY, Goldman RD, Eriksson JE. 2014. Interphase phosphorylation of lamin A. J Cell Sci 127: 2683-2696.

Kohwi M, Lupton JR, Lai SL, Miller MR, Doe CQ. 2013. Developmentally regulated subnuclear genome reorganization restricts neural progenitor competence in Drosophila. Cell 152: $97-108$.

Kolb T, Maass K, Hergt M, Aebi U, Herrmann H. 2011. Lamin A and lamin $\mathrm{C}$ form homodimers and coexist in higher complex forms both in the nucleoplasmic fraction and in the lamina of cultured human cells. Nucleus 2: 425-433.

Korfali N, Wilkie GS, Swanson SK, Srsen V, de Las Heras J, Batrakou DG, Malik P, Zuleger N, Kerr AR, Florens L, et al. 2012. The nuclear envelope proteome differs notably between tissues. Nucleus 3: 552-564.

Krimm I, Ostlund C, Gilquin B, Couprie J, Hossenlopp P, Mornon JP, Bonne G, Courvalin JC, Worman HJ, Zinn-Justin S. 2002. The Ig-like structure of the C-terminal domain of lamin A/C, mutated in muscular dystrophies, cardiomyopathy, and partial lipodystrophy. Structure 10: 811-823.

Kubben N, Voncken JW, Konings G, van Weeghel M, van den Hoogenhof MM, Gijbels M, van Erk A, Schoonderwoerd K, van den Bosch B, Dahlmans V, et al. 2011. Post-natal myogenic and adipogenic developmental: defects and metabolic impairment upon loss of A-type lamins. Nucleus 2: 195-207.

Kuga T, Nozaki N, Matsushita K, Nomura F, Tomonaga T. 2010. Phosphorylation statuses at different residues of lamin B2, $\mathrm{B} 1$, and $\mathrm{A} / \mathrm{C}$ dynamically and independently change throughout the cell cycle. Exp Cell Res 316: 2301-2312.

Lammerding J, Schulze PC, Takahashi T, Kozlov S, Sullivan T, Kamm RD, Stewart CL, Lee RT. 2004. Lamin A/C deficiency causes defective nuclear mechanics and mechanotransduction. J Clin Invest 113: 370-378.

Lammerding J, Hsiao J, Schulze PC, Kozlov S, Stewart CL, Lee RT. 2005. Abnormal nuclear shape and impaired mechanotransduction in emerin-deficient cells. J Cell Biol 170: 781-791.

Lammerding J, Fong LG, Ji JY, Reue K, Stewart CL, Young SG, Lee RT. 2006. Lamins A and C but not lamin B1 regulate nuclear mechanics. J Biol Chem 281: 25768-25780.

Leckband DE, de Rooij J. 2014. Cadherin adhesion and mechanotransduction. Annu Rev Cell Dev Biol 30: 291-315.

Lee JS, Hale CM, Panorchan P, Khatau SB, George JP, Tseng Y, Stewart CL, Hodzic D, Wirtz D. 2007. Nuclear lamin A/C deficiency induces defects in cell mechanics, polarization, and migration. Biophys J 93: 2542-2552.
Lin F, Morrison JM, Wu W, Worman HJ. 2005. MAN1, an integral protein of the inner nuclear membrane, binds Smad2 and Smad 3 and antagonizes transforming growth factor- $\beta$ signaling. Hum Mol Genet 14: 437-445.

Liu J, Lee KK, Segura-Totten M, Neufeld E, Wilson KL, Gruenbaum Y. 2003. MAN1 and emerin have overlapping function(s) essential for chromosome segregation and cell division in Caenorhabditis elegans. Proc Natl Acad Sci 100: 4598-4603.

Lombardi ML, Jaalouk DE, Shanahan CM, Burke B, Roux KJ, Lammerding J. 2011. The interaction between nesprins and sun proteins at the nuclear envelope is critical for force transmission between the nucleus and cytoskeleton. I Biol Chem 286: 26743-26753.

Lund E, Oldenburg AR, Delbarre E, Freberg CT, Duband-Goulet I, Eskeland R, Buendia B, Collas P. 2013. Lamin A/C-promoter interactions specify chromatin state-dependent transcription outcomes. Genome Res 10: 1580-1590.

Luxton GW, Gomes ER, Folker ES, Vintinner E, Gundersen GG. 2010. Linear arrays of nuclear envelope proteins harness retrograde actin flow for nuclear movement. Science 329: 956-959.

Mall M, Walter T, Gorjanacz M, Davidson IF, Nga Ly-Hartig TB, Ellenberg J, Mattaj IW. 2012. Mitotic lamin disassembly is triggered by lipid-mediated signaling. I Cell Biol 198: 981990.

Maniotis AJ, Chen CS, Ingber DE. 1997. Demonstration of mechanical connections between integrins, cytoskeletal filaments, and nucleoplasm that stabilize nuclear structure. Proc Natl Acad Sci 94: 849-854.

Marenzana M, Wilson-Jones N, Mudera V, Brown RA. 2006. The origins and regulation of tissue tension: identification of collagen tension-fixation process in vitro. Exp Cell Res 312: 423-433.

Margulies KB, Bednarik DP, Dries DL. 2009. Genomics, transcriptional profiling, and heart failure. J Am Coll Cardiol 53: 1752-1759.

Markiewicz E, Dechat T, Foisner R, Quinlan RA, Hutchison CJ. 2002. Lamin A/C binding protein LAP $2 \alpha$ is required for nuclear anchorage of retinoblastoma protein. Mol Biol Cell 13: 4401-4413.

Markiewicz E, Tilgner K, Barker N, van de Wetering M, Clevers H, Dorobek M, Hausmanowa-Petrusewicz I, Ramaekers FC, Broers JL, Blankesteijn WM, et al. 2006. The inner nuclear membrane protein emerin regulates $\beta$-catenin activity by restricting its accumulation in the nucleus. EMBO I 25: 3275-3285.

Mattout A, Pike BL, Towbin BD, Bank EM, Gonzalez-Sandoval A, Stadler MB, Meister P, Gruenbaum Y, Gasser SM. 2011. An EDMD mutation in C. elegans lamin blocks muscle-specific gene relocation and compromises muscle integrity. Curr Biol 21: $1603-1614$.

Meinke P, Mattioli E, Haque F, Antoku S, Columbaro M, Straatman KR, Worman HJ, Gundersen GG, Lattanzi G, Wehnert M, et al. 2014. Muscular dystrophy-associated SUN1 and SUN2 variants disrupt nuclear-cytoskeletal connections and myonuclear organization. PLOS Genet 10: e1004605.

Meister P, Towbin BD, Pike BL, Ponti A, Gasser SM. 2010. The spatial dynamics of tissue-specific promoters during C. elegans development. Genes Dev 24: 766-782.

Mejat A, Misteli T. 2010. LINC complexes in health and disease. Nucleus 1: 40-52.

Melcer S, Gruenbaum Y, Krohne G. 2007. Invertebrate lamins. Exp Cell Res 313: 2157-2166.

Meyer-ter-Vehn T, Sieprath S, Katzenberger B, Gebhardt S, Grehn F, Schlunck G. 2006. Contractility as a prerequisite for TGF- $\beta$-induced myofibroblast transdifferentiation in human tenon fibroblasts. Invest Ophthalmol Vis Sci 47: 4895-4904. 
Miralles F, Posern G, Zaromytidou AI, Treisman R. 2003. Actin dynamics control SRF activity by regulation of its coactivator MAL. Cell 113: 329-342.

Mitsuhashi H, Hayashi YK, Matsuda C, Noguchi S, Wakatsuki S, Araki T, Nishino I. 2010. Specific phosphorylation of Ser458 of A-type lamins in LMNA-associated myopathy patients. J Cell Sci 123: 3893-3900.

Moir RD, Yoon M, Khuon S, Goldman RD. 2000. Nuclear lamins $\mathrm{A}$ and $\mathrm{B} 1$ : different pathways of assembly during nuclear envelope formation in living cells. J Cell Biol 151: 1155-1168.

Mouilleron S, Guettler S, Langer CA, Treisman R, McDonald NQ. 2008. Molecular basis for G-actin binding to RPEL motifs from the serum response factor coactivator MAL. EMBO J 27: 3198-3208.

Naetar N, Foisner R. 2009. Lamin complexes in the nuclear interior control progenitor cell proliferation and tissue homeostasis. Cell Cycle 8: 1488-1493.

Naetar N, Korbei B, Kozlov S, Kerenyi MA, Dorner D, Kral R, Gotic I, Fuchs P, Cohen TV, Bittner R, et al. 2008. Loss of nucleoplasmic LAP2 $\alpha$-lamin A complexes causes erythroid and epidermal progenitor hyperproliferation. Nat Cell Biol 10: $1341-1348$.

Nikolova V, Leimena C, McMahon AC, Tan JC, Chandar S, Jogia D, Kesteven SH, Michalicek J, Otway R, Verheyen F, et al. 2004. Defects in nuclear structure and function promote dilated cardiomyopathy in lamin A/C-deficient mice. I Clin Invest 113: 357-369.

Olive M, Harten I, Mitchell R, Beers JK, Djabali K, Cao K, Erdos MR, Blair C, Funke B, Smoot L, et al. 2010. Cardiovascular pathology in Hutchinson-Gilford progeria: correlation with the vascular pathology of aging. Arterioscler Thromb Vasc Biol 30: 2301-2309.

Pajerowski JD, Dahl KN, Zhong FL, Sammak PJ, Discher DE. 2007. Physical plasticity of the nucleus in stem cell differentiation. Proc Natl Acad Sci 104: 15619-15624.

Panorchan P, Schafer BW, Wirtz D, Tseng Y. 2004a. Nuclear envelope breakdown requires overcoming the mechanical integrity of the nuclear lamina. I Biol Chem 279: 4346243467.

Panorchan P, Wirtz D, Tseng Y. 2004b. Structure-function relationship of biological gels revealed by multiple-particle tracking and differential interference contrast microscopy: the case of human lamin networks. Phys Rev E Stat Nonlin Soft Matter Phys 70: 041906.

Pekovic V, Harborth J, Broers JL, Ramaekers FC, van Engelen B, Lammens $M$, von Zglinicki $T$, Foisner R, Hutchison $C$, Markiewicz E. 2007. Nucleoplasmic LAP2 $\alpha$-lamin A complexes are required to maintain a proliferative state in human fibroblasts. I Cell Biol 176: 163-172.

Pendas AM, Zhou Z, Cadinanos J, Freije JM, Wang J, Hultenby $\mathrm{K}$, Astudillo A, Wernerson A, Rodriguez F, Tryggvason K, et al. 2002. Defective prelamin A processing and muscular and adipocyte alterations in Zmpste24 metalloproteinasedeficient mice. Nat Genet 31: 94-99.

Peric-Hupkes D, Meuleman W, Pagie L, Bruggeman SW, Solovei I, Brugman W, Graf S, Flicek P, Kerkhoven RM, van Lohuizen $M$, et al. 2010. Molecular maps of the reorganization of genome-nuclear lamina interactions during differentiation. Mol Cell 38: 603-613.

Poh YC, Shevtsov SP, Chowdhury F, Wu DC, Na S, Dundr M, Wang N. 2012. Dynamic force-induced direct dissociation of protein complexes in a nuclear body in living cells. Nat Commun 3: 866.

Prokocimer M, Davidovich M, Nissim-Rafinia M, WieselMotiuk N, Bar D, Barkan R, Meshorer E, Gruenbaum Y.
2009. Nuclear lamins: key regulators of nuclear structure and activities. J Cell Mol Med 6: 1059-1085.

Rashmi RN, Eckes B, Glockner G, Groth M, Neumann S, Gloy J, Sellin L, Walz G, Schneider M, Karakesisoglou I, et al. 2012. The nuclear envelope protein Nesprin-2 has roles in cell proliferation and differentiation during wound healing. $\mathrm{Nu}$ cleus 3: 172-186.

Reichel W, Garcia-Bunuel R. 1970. Pathologic findings in progeria: myocardial fibrosis and lipofuscin pigment. Am I Clin Pathol 53: 243-253.

Rodriguez J, Calvo F, Gonzalez JM, Casar B, Andres V, Crespo P. 2010. ERK1/2 MAP kinases promote cell cycle entry by rapid, kinase-independent disruption of retinoblastomalamin A complexes. J Cell Biol 191: 967-979.

Rowat AC, Lammerding J, Ipsen JH. 2006. Mechanical properties of the cell nucleus and the effect of emerin deficiency. Biophys J 91: 4649-4664.

Rowat AC, Jaalouk DE, Zwerger M, Ung WL, Eydelnant IA, Olins DE, Olins AL, Herrmann H, Weitz DA, Lammerding J. 2013. Nuclear envelope composition determines the ability of neutrophil-type cells to passage through micron-scale constrictions. J Biol Chem 288: 8610-8618.

Rusinol AE, Sinensky MS. 2006. Farnesylated lamins, progeroid syndromes and farnesyl transferase inhibitors. J Cell Sci 119: 3265-3272.

Scaffidi P, Misteli T. 2008. Lamin A-dependent misregulation of adult stem cells associated with accelerated ageing. Nat Cell Biol 10: 452-459.

Schermelleh L, Carlton PM, Haase S, Shao L, Winoto L, Kner P, Burke B, Cardoso MC, Agard DA, Gustafsson MG, et al. 2008. Subdiffraction multicolor imaging of the nuclear periphery with 3D structured illumination microscopy. Science 320: 1332-1336.

Schirmer EC, Guan T, Gerace L. 2001. Involvement of the lamin rod domain in heterotypic lamin interactions important for nuclear organization. J Cell Biol 153: 479-489.

Schneider U, Mini T, Jeno P, Fisher PA, Stuurman N. 1999. Phosphorylation of the major Drosophila lamin in vivo: site identification during both M-phase (meiosis) and interphase by electrospray ionization tandem mass spectrometry. Biochemistry 38: 4620-4632.

Schreiber KH, Kennedy BK. 2013. When lamins go bad: nuclear structure and disease. Cell 152: 1365-1375.

Schwartz MA. 2009. Cell biology. The force is with us. Science 323: $588-589$.

Shevelyov YY, Lavrov SA, Mikhaylova LM, Nurminsky ID, Kulathinal RJ, Egorova KS, Rozovsky YM, Nurminsky DI. 2009. The B-type lamin is required for somatic repression of testis-specific gene clusters. Proc Natl Acad Sci 106: 32823287.

Shimi T, Goldman RD. 2014. Nuclear lamins and oxidative stress in cell proliferation and longevity. Adv Exp Med Biol 773: 415-430.

Shimi T, Pfleghaar K, Kojima S, Pack CG, Solovei I, Goldman AE, Adam SA, Shumaker DK, Kinjo M, Cremer T, et al. 2008. The A- and B-type nuclear lamin networks: microdomains involved in chromatin organization and transcription. Genes Dev 22: 3409-3421.

Shin JW, Spinler KR, Swift J, Chasis JA, Mohandas N, Discher DE. 2013. Lamins regulate cell trafficking and lineage maturation of adult human hematopoietic cells. Proc Natl Acad Sci 110: 18892-18897.

Shumaker DK, Solimando L, Sengupta K, Shimi T, Adam SA, Grunwald A, Strelkov SV, Aebi U, Cardoso MC, Goldman RD. 2008. The highly conserved nuclear lamin Ig-fold binds to PCNA: its role in DNA replication. J Cell Biol 181: 269-280. 
Simon DN, Wilson KL. 2011. The nucleoskeleton as a genomeassociated dynamic 'network of networks'. Nat Rev Mol Cell Biol 12: 695-708.

Simon DN, Wilson KL. 2013. Partners and post-translational modifications of nuclear lamins. Chromosoma 122: 13-31.

Solovei I, Wang AS, Thanisch K, Schmidt CS, Krebs S, Zwerger M, Cohen TV, Devys D, Foisner R, Peichl L, et al. 2013. LBR and lamin $\mathrm{A} / \mathrm{C}$ sequentially tether peripheral heterochromatin and inversely regulate differentiation. Cell 152: 584-598.

Sosa BA, Rothballer A, Kutay U, Schwartz TU. 2012. LINC complexes form by binding of three KASH peptides to domain interfaces of trimeric SUN proteins. Cell 149: 1035-1047.

Steen RL, Martins SB, Tasken K, Collas P. 2000. Recruitment of protein phosphatase 1 to the nuclear envelope by A-kinase anchoring protein AKAP149 is a prerequisite for nuclear lamina assembly. J Cell Biol 150: 1251-1262.

Stuurman N, Sasse B, Fisher PA. 1996. Intermediate filament protein polymerization: molecular analysis of Drosophila nuclear lamin head-to-tail binding. I Struct Biol 117: 1-15.

Stuurman N, Heins S, Aebi U. 1998. Nuclear lamins: their structure, assembly, and interactions. J Struct Biol 122: 42-66.

Suh Y, Kennedy BK. 2012. Dialing down SUN1 for laminopathies. Cell 149: 509-510.

Sullivan T, Escalante-Alcalde D, Bhatt H, Anver M, Bhat N, Nagashima K, Stewart CL, Burke B. 1999. Loss of A-type lamin expression compromises nuclear envelope integrity leading to muscular dystrophy. J Cell Biol 147: 913-920.

Sun Y, Li W, Lu Z, Chen R, Ling J, Ran Q, Jilka RL, Chen XD. 2011. Rescuing replication and osteogenesis of aged mesenchymal stem cells by exposure to a young extracellular matrix. FASEB J 25: 1474-1485.

Swift J, Ivanovska IL, Buxboim A, Harada T, Dingal PC, Pinter J, Pajerowski JD, Spinler KR, Shin JW, Tewari M, et al. 2013. Nuclear lamin-A scales with tissue stiffness and enhances matrix-directed differentiation. Science 341: 1240104.

Tapley EC, Starr DA. 2013. Connecting the nucleus to the cytoskeleton by SUN-KASH bridges across the nuclear envelope. Curr Opin Cell Biol 25: 57-62.

Thompson LJ, Bollen M, Fields AP. 1997. Identification of protein phosphatase 1 as a mitotic lamin phosphatase. I Biol Chem 272: 29693-29697.

Tilgner K, Wojciechowicz K, Jahoda C, Hutchison C, Markiewicz E. 2009. Dynamic complexes of A-type lamins and emerin influence adipogenic capacity of the cell via nucleocytoplasmic distribution of $\beta$-catenin. J Cell Sci 122: 401-413.

Towbin BD, Meister P, Pike BL, Gasser SM. 2010. Repetitive transgenes in C. elegans accumulate heterochromatic marks and are sequestered at the nuclear envelope in a copy-numberand lamin-dependent manner. Cold Spring Harb Symp Quant Biol 75: 555-565.

Tzima E, Irani-Tehrani M, Kiosses WB, Dejana E, Schultz DA, Engelhardt B, Cao G, DeLisser H, Schwartz MA. 2005. A mechanosensory complex that mediates the endothelial cell response to fluid shear stress. Nature 437: 426-431.

Van Berlo JH, Voncken JW, Kubben N, Broers JL, Duisters R, van Leeuwen RE, Crijns HJ, Ramaekers FC, Hutchison CJ, Pinto YM. 2005. A-type lamins are essential for TGF- $\beta 1$ induced PP2A to dephosphorylate transcription factors. Hum Mol Genet 14: 2839-2849.

Vaughan A, Alvarez-Reyes M, Bridger JM, Broers JL, Ramaekers FC, Wehnert M, Morris GE, Whitfield WGF, Hutchison CJ. 2001. Both emerin and lamin C depend on lamin A for localization at the nuclear envelope. J Cell Sci 114: 2577-2590.

Vergnes L, Peterfy M, Bergo MO, Young SG, Reue K. 2004. Lamin B1 is required for mouse development and nuclear integrity. Proc Natl Acad Sci 101: 10428-10433.
Wang Y, Botvinick EL, Zhao Y, Berns MW, Usami S, Tsien RY, Chien S. 2005. Visualizing the mechanical activation of Src. Nature 434: 1040-1045.

Wang N, Tytell JD, Ingber DE. 2009a. Mechanotransduction at a distance: mechanically coupling the extracellular matrix with the nucleus. Nat Rev Mol Cell Biol 10: 75-82.

Wang Y, Flores L, Lu S, Miao H, Li YS, Chien S. 2009b. Shear stress regulates the Flk-1/Cbl/PI3K/NF-кB pathway via actin and tyrosine kinases. Cell Mol Bioeng 2: 341-350.

Wiesel N, Mattout A, Melcer S, Melamed-Book N, Herrmann H, Medalia O, Aebi U, Gruenbaum Y. 2008. Laminopathic mutations interfere with the assembly, localization, and dynamics of nuclear lamins. Proc Natl Acad Sci 105: 180185.

Wolfenson H, Lavelin I, Geiger B. 2013. Dynamic regulation of the structure and functions of integrin adhesions. Dev Cell 24: 447-458.

Worman HJ. 2012. Nuclear lamins and laminopathies. J Pathol 226: 316-325.

Wu D, Flannery AR, Cai H, Ko E, Cao K. 2014. Nuclear localization signal deletion mutants of lamin A and progerin reveal insights into lamin A processing and emerin targeting. Nucleus 5: 66-74.

Yao M, Qiu W, Liu R, Efremov AK, Cong P, Seddiki R, Payre M, Lim CT, Ladoux B, Mege RM, et al. 2014. Force-dependent conformational switch of $\alpha$-catenin controls vinculin binding. Nat Commun 5: 4525.

Young SG, Fong LG, Michaelis S. 2005. Prelamin A, Zmpste24, misshapen cell nuclei, and progeria-new evidence suggesting that protein farnesylation could be important for disease pathogenesis. I Lipid Res 46: 2531-2558.

Zaremba-Czogalla M, Piekarowicz K, Wachowicz K, Koziol K, Dubinska-Magiera M, Rzepecki R. 2012. The different function of single phosphorylation sites of Drosophila melanogaster lamin Dm and lamin C. PLOS ONE 7: e32649.

Zhavoronkov A, Smit-McBride Z, Guinan KJ, Litovchenko M, Moskalev A. 2012. Potential therapeutic approaches for modulating expression and accumulation of defective lamin A in laminopathies and age-related diseases. J Mol Med (Berl) 90: $1361-1389$.

Zuela N, Bar DZ, Gruenbaum Y. 2012. Lamins in development, tissue maintenance and stress. EMBO Rep 13: 1070-1078.

Zwerger M, Medalia O. 2013. From lamins to lamina: a structural perspective. Histochem Cell Biol 140: 3-12.

Zwerger $M$, Jaalouk DE, Lombardi ML, Isermann $P$, Mauermann M, Dialynas G, Herrmann H, Wallrath LL, Lammerding J. 2013. Myopathic lamin mutations impair nuclear stability in cells and tissue and disrupt nucleo-cytoskeletal coupling. Hum Mol Genet 22: 2335-2349. 


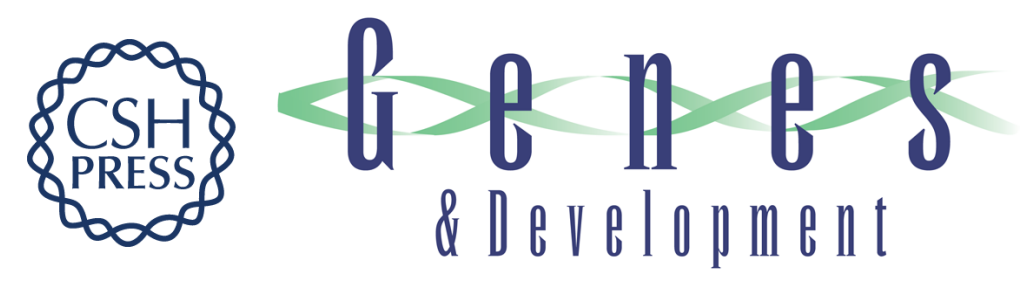

\section{Lamins at the crossroads of mechanosignaling}

Selma Osmanagic-Myers, Thomas Dechat and Roland Foisner

Genes Dev. 2015, 29:

Access the most recent version at doi:10.1101/gad.255968.114

References This article cites 185 articles, 78 of which can be accessed free at: http://genesdev.cshlp.org/content/29/3/225.full.html\#ref-list-1

Creative This article, published in Genes \& Development, is available under a Creative Commons

Commons License (Attribution-NonCommercial 4.0 International), as described at

License http://creativecommons.org/licenses/by-nc/4.0/.

Email Alerting Receive free email alerts when new articles cite this article - sign up in the box at the top Service right corner of the article or click here.

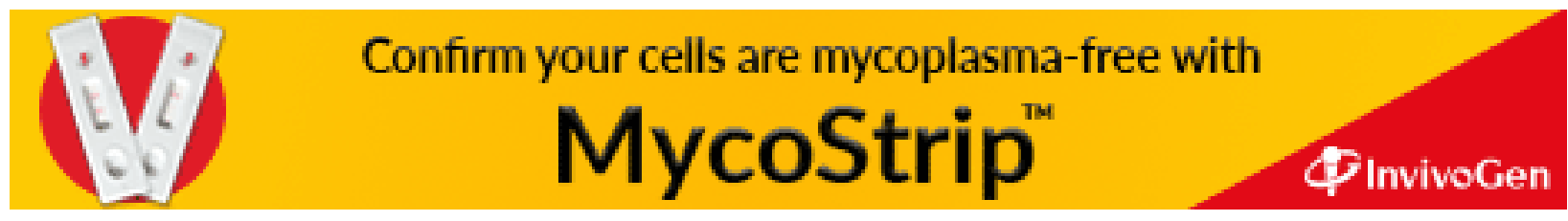

